\title{
Percepção dos impactos ambientais dos domissanitários: Resultados do projeto de extensão com grupos de mulheres das comunidades de Garopaba e Imbituba
}

Victória Brito Jurquet ${ }^{1}$

\begin{abstract}
Resumo: O presente artigo descreve e analisa a atividade de extensão realizada no município de Garopaba e Imbituba a respeito da percepção dos impactos ambientais dos domissanitários. Foram realizadas oficinas a respeito dos produtos domissanitários, seus impactos ambientais, como utilizá-los e a fabricação de produtos que podem ser utilizados em higienização. As atividades foram realizadas em três fases, um questionário para obter informações sobre o conhecimento prévio das participantes, a realização de uma exposição dialogada e um questionário de avaliação. A pesquisa apontou que há falta de conhecimento sobre os impactos ambientais causados pelo uso de produtos domissanitários, também o desconhecimento das normas de manipulação dos produtos, armazenamento e descarte e que a maioria dos pesquisados não utiliza Equipamento de Proteção Individual (EPI). Com a atividade de extensão conseguiu-se sensibilizar a comunidade quanto aos impactos ambientais e sociais causados pelos domissanitários.
\end{abstract}

Palavras-chave: Produtos domissanitários. Educação ambiental. Extensão universitária.

Área Temática: Educação; Meio ambiente.

\section{Perceptions of the environmental impact of cleaning supplies: Results of the extension program studies carried out with groups of women from Garopaba and Imbituba communities}

\begin{abstract}
This article describes and analyzes the extension activity carried out in the municipality of Garopaba and Imbituba regarding the perception of the environmental impacts of household cleaning products. Workshops were held about household cleaning products, their environmental impacts, how to use them, and the manufacture of products that can be used in sanitation. The activities were carried out in three phases, a questionnaire to obtain information about the participants' prior knowledge, a dialogued exposition, and an evaluation questionnaire. The survey pointed out a lack of knowledge about the environmental impacts caused by the use of household cleaning products, the ignorance of the rules for handling the products, storage, and disposal, and that most respondents do not use Personal Protective Equipment (PPE). With the extension activity, it was possible to sensitize the community about the environmental and social impacts caused by household cleaning services.
\end{abstract}

Keywords: Education; Environmental.

\section{Percepciones del impacto ambiental de los productos de limpieza domestica: Resultados del programa de extensión con grupos de mujeres de las comunidades de Garopaba e Imbituba}

Resumen: Este artículo describe y analiza la actividad de extensión que se realiza en el municipio de Garopaba e Imbituba sobre la percepción de los impactos ambientales de los productos de limpieza del hogar. Se realizaron talleres sobre 
productos de limpieza del hogar, sus impactos ambientales, cómo usarlos y la fabricación de productos que pueden ser utilizados en saneamiento. Las actividades se realizaron en tres fases, un cuestionario para obtener información sobre los conocimientos previos de los participantes, una exposición dialogada y un cuestionario de evaluación. La encuesta señaló que existe un desconocimiento sobre los impactos ambientales causados por el uso de productos de limpieza del hogar, también el desconocimiento de las reglas para el manejo, almacenamiento y eliminación de los productos y que la mayoría de los encuestados no utilizan Equipo de Protección Personal (EPI). Con la actividad de extensión se logró sensibilizar a la comunidad sobre los impactos ambientales y sociales que ocasionan los servicios de limpieza domiciliaria.

Palabras clave: Educación; Meio Ambiente.

\section{INTRODUÇÃO}

Produtos de limpeza, também chamados de domissanitários, são produzidos desde a idade média, mas foram popularizados após a $2^{\text {a }}$ Guerra Mundial. Para que seu custo fosse barateado suas fórmulas foram cada vez mais aprimoradas, visando um melhor desempenho e barateamento do produto (CORRÊA, 2005).

Hoje em dia existem diversos fabricantes, que os classificam segundo a função daquilo que se quer nele destacar, ou seja, sua utilização em cada categoria de sujeira, material e superfície (MARTINS, 2009). Por outro lado, a Agência Nacional de Vigilância Sanitária (ANVISA) classifica os domissanitários em relação à sua dimensão saneante, desinfetante e higienizante.

São constituídos por produtos químicos que quando utilizados de forma incorreta causam diversos problemas ambientais e a saúde humana. Estes produtos são geradores de toxicidade em seres humanos e animais, devido a sua utilização constante e a falta de saneamento adequado nas cidades os domissanitários acabam atingindo mananciais elevando o índice de contaminação das águas (SOUZA et al, 2015).

O Sistema Nacional de Informação Tóxico-Farmacológica (Sinitox) em 2001 realizou uma estatística anual de casos de intoxicação e envenenamento no Centro de Informações Científica e Tecnológica da Fundação Oswaldo Cruz em que, dentre os oito principais agentes de intoxicação, os domissanitários apresentam o segundo maior índice de internação (9\%), ficando atrás apenas dos medicamentos (26\%).

Em contraposição aos produtos de limpeza convencionais está surgindo, atualmente, uma nova tendência no mercado dos produtos de limpeza em que, na sua composição vêm sendo empregado reagentes ecologicamente corretos (ecofriendly), isto é, que adotam os requisitos da biodegradabilidade e a não toxicidade, ou uma toxicidade mínima para os organismos vivos (NUNES; SILVA, 2011).

Com a reflexão a respeito dos impactos ambientais dos domissanitários as universidades, constituem se espaços adequados para estabelecer uma interação com a comunidade. Assim torna-se importante estudar os impactos ambientais e difundir para a população o conhecimento a respeito dos produtos domissanitários.

Auniversidade é constituída por três pilares indissociáveis, previsto no artigo 207 da Constituição Federal de 1988, sendo eles ensino, pesquisa e extensão. O ensino é a difusão do conhecimento entre docentes e discentes, a pesquisa é a produção tecno-científica e a extensão é a difusão para a comunidade dos conhecimentos gerados nas universidades (HUNGER et al., 2014). 
O Fórum de Pró-Reitorias de Extensão das Universidades Públicas brasileiras e a secretaria do Ensino Superior do Ministério da Educação e do Desporto elaboraram o Plano Nacional de Extensão que prevê a extensão como a viabilização da relação transformadora entre universidade e sociedade. Assim a universidade difunde o seu conhecimento e oferta os seus serviços exercendo sua função de melhorar a qualidade de vida dos cidadãos (NUNES; SILVA, 2011).

Dessa forma, o presente artigo relata e analisa o desenvolvimento de um projeto de extensão realizado no Instituto Federal de Santa Catarina (IFSC) - Garopaba (SC) por meio do edital de Protagonismo Discente PROEX 16/2019, que teve como público-alvo a comunidade local de Garopaba, sendo especificamente grupos já formados compostos por mães e Mulheres Sim. Ainda tendo como piloto o desenvolvimento da atividade com o Centro de Atenção Psicossocial (CAPS). Em análise bibliográfica, notou-se que as exposições tóxicas relacionadas a domissanitários são relativamente comuns para mulheres adultas, adolescentes e, sobretudo crianças no Brasil, os acidentes tóxicos são um dos principais motivos para internação (FOOK et al, 2013). Além disso, segundo pesquisa do Instituto Brasileiro de Geografia e Estatística (IBGE) (2018), as mulheres dedicam 21,3 horas por semana aos afazeres domésticos, quase o dobro do que os homens gastam com as mesmas tarefas 10,9 horas por semana.

Para realizar a proposta, partiu-se de uma problematização inicial: Qual é a percepção ambiental dos participantes do projeto de extensão “difundindo uma cultura de domissanitários ecologicamente corretos” a respeito dos produtos domissanitários? Tendo como objetivo estimular o diálogo a respeito dos produtos domissanitários e seus impactos através de oficinas realizadas na comunidade de Garopaba e Imbituba e específicos avaliar os resultados das atividades realizadas com os participantes do PROEX 16/2019 sobre os impactos ambientais dos produtos de limpeza; levar a educação ambiental para além das universidades.

Com a coleta de dados e as oficinas realizadas pelo Projeto de extensão, este artigo objetivou avaliar os resultados das atividades realizadas com os participantes do PROEX 16/2019 sobre os impactos ambientais dos produtos de limpeza. Já que existe uma enorme lacuna de conhecimento da população em relação ao conteúdo dos domissanitários, seu uso correto, impactos no meio ambiente e na saúde (BRAMANTE; LOURENÇO; CANDIANI, 2017). Além disso, pela necessidade de levar a educação ambiental para além das universidades, trazendo um maior conhecimento para o público usuário destes produtos.

\section{Conceituação dos produtos domissanitários}

Os produtos químicos são associados pela população a uma realidade distante, como se eles fossem exclusivamente presentes em de laboratórios (PINHEIRO et al., 2014). Entretanto, diversos produtos químicos são utilizados diariamente pela população, alguns exemplos são: cosméticos, perfumes, produtos de limpeza (domissanitários) e alimentos.

Os domissanitários são produtos químicos criados para a aplicação em limpezas gerais (MARTINS, 2009). São usados para a manutenção da limpeza e conservação de ambientes urbanos (públicos e privados) geralmente os agentes químicos com poder de desinfecção. 
São exemplos de domissanitários os detergentes e seus congêneres, alvejantes, água sanitária, desinfetantes, desodorizantes aromatizantes de ambientes, desentupidores, desengraxantes, polidores de metais, de sapatos e de móveis, removedores de manchas e de ferrugem, esterilizantes, algicidas e fungicidas para piscinas, inseticidas, raticidas, produtos para jardinagem amadora, repelentes (PINHEIRO et al, 2014). Nota-se que no mercado encontram-se produtos, destinados cada um a determinado ambiente e superfície, e alguns deles têm a mesma função (MARTINS, 2009).

Na composição dos produtos domissanitários, muitas vezes, estão presentes substâncias cáusticas, como as exemplificadas por Fook et al. (2013, p.2): “em detergentes (cloreto de benzalcônio), antissépticos (fenol), desinfetantes (ácido oxálico), desodorizantes (ácido fórmico) e alvejantes (hipoclorito de sódio)"

Os surfactantes, também conhecido como tensoativos, presentes nos domissanitários são substâncias químicas orgânicas anfipáticas fabricadas por síntese, ou seja, juntadas quimicamente a partir de uma grande variedade de matérias-primas, sua ação provoca a diminuição da tensão superficial da água facilitando o processo de lavagem (FELIPE; DIAS, 2016).

No Brasil, os produtos de limpeza são regulamentados pela ANVISA através da Resolução da Diretoria Colegiada (RDC) $N^{\circ} 43$ que fala sobre as regras estabelecidas pelo Ministério da Saúde e ANVISA sobre as embalagens, rótulos, importação e aspectos técnicos. AANVISA na RDC N ${ }^{\circ} 55$ classifica os domissanitários conforme mostra a Quadro 1:

Quadro 1 - Classificação dos produtos domissanitários

\begin{tabular}{|l|l|}
\hline Produto & \multicolumn{1}{c|}{ Classificação } \\
\hline Água Sanitária & $\begin{array}{l}\text { Soluções aquosas à base de hipoclorito de sódio ou cálcio, com teor de cloro ativo } \\
\text { entre 2,0 a 2,5\% p/p, durante o prazo de validade (máximo de } 6 \text { meses). O produto } \\
\text { poderá conter apenas hidróxido de sódio ou cálcio, cloreto de sódio ou cálcio e } \\
\text { carbonato de sódio ou cálcio como estabilizante. Pode ter ação como alvejante e } \\
\text { desinfetante de uso geral. }\end{array}$ \\
\hline Alvejante & $\begin{array}{l}\text { Qualquer substância com ação química, oxidante ou redutora, que exerce ação } \\
\text { branqueadora. }\end{array}$ \\
\hline Desinfetante & $\begin{array}{l}\text { São formulações que têm na sua composição substâncias microbicidas e apresentam } \\
\text { efeito letal para microrganismos não esporulados. }\end{array}$ \\
\hline Desodorizantes & $\begin{array}{l}\text { São formulações que têm na sua composição substâncias microbiostáticas, capazes de } \\
\text { controlar os odores desagradáveis advindos do metabolismo microorgânico. Não } \\
\text { apresentam efeito letal sobre microrganismos, mas inibemo seu crescimentoe multiplicação. }\end{array}$ \\
\hline Detergentes & $\begin{array}{l}\text { Soluções aquosas à base de hipoclorito de sódio ou cálcio, com teor de cloro ativo } \\
\text { entre 2,0 a 2,5\% p/p, durante o prazo de validade (máximo de 6 meses). O produto poderá } \\
\text { conter apenas hidróxido de sódio ou cálcio, cloreto de sódio ou cálcio e carbonato de } \\
\text { sódio ou cálcio como estabilizante. Pode ter ação como alvejante e desinfetante de uso } \\
\text { geral. }\end{array}$ \\
\hline
\end{tabular}

Fonte: ANVISA, 2009. 
Na Resolução da Diretoria Colegiada $N^{\circ} 43$, os produtos são classificados como de risco I e risco II. Os produtos de risco I, mais simples, são classificados como alvejantes, branqueadores, desincrustantes, detergentes, amaciantes, lustradores, cera para piso, produtos para lavagem de roupas como amaciantes, perfumadores, desengordurantes, sabões saponáceos e outras. Já os produtos de risco II, que necessitam de análise técnica, são os desinfetantes, desodorantes, esterilizantes, água sanitária e outros (ANVISA, 2016).

Além disso, a Anvisa também classifica os produtos conforme o seu uso. Para uso doméstico a recomendação de produtos destinados “a desodorização/sanitização/desinfecção de pisos, paredes, mobiliários e outras superfícies, ambientes, sanitários e utensílios que não entrem em contato com alimentos” ANVISA (2016, p.7)

De acordo com a Resolução de Diretoria Colegiada N 14 da ANVISA(2007, p.3) os desinfetantes são classificados como "um produto que mata todos os microrganismos patogênicos, mas não necessariamente todas as formas microbianas esporuladas em objetos e superfícies inanimadas", os sanitizantes como "um agente/ produto que reduz o número de bactérias a níveis seguros de acordo com as normas de saúde" e os desodorantes como "produto que tem em sua composição substância com atividade antimicrobiana capaz de controlar odores desagradáveis."

Para a comercialização destes produtos são adicionados diversos agentes químicos para conciliar um aumento na eficiência da lavagem com a redução do custo global, tais como os coadjuvantes - abrasivos, ácidos, solventes, álcalis, enzimas, heterotópicos, anticalcários, reguladores de espuma (estabilizantes e supressores), reforçadores, anti depositantes e amaciantes -, os aditivos inibidores de corrosão e inibidores de manchas, os branqueadores (óticos e químicos) e os abrilhantadores de tecido (de ação amaciante), os agentes antimicrobianos, os conservantes, os opacificantes, os corantes e perfumes, e demais materiais inertes (CORRÊA, 2005). Porém, muitos desses agentes provocam fortes impactos ambientais, e sérios danos à saúde humana, exigindo-se limitações contra sua utilização exagerada.

\section{Impactos ambientais e alternativas}

Os produtos de limpeza sempre estiveram atrelados a problemas ambientais (ALIGLERI, ALIGLERI; KRUGLIANSKAS, 2016). O cloro está presente em cerca de 70\% de todos os produtos químicos, ou participa como reagente, em pelo menos uma etapa do processo de fabricação (MARTINS, 2009). Substâncias que contém derivados do cloro quando em contato com a água e matéria orgânica, ácidos húmicos e fúlvicos, naturalmente presentes na água formam os organoclorados, substância com efeitos mutagênicos em diferentes espécies animais (BARBOSA, 2009).

Outro agravante relacionado às substâncias à base de cloro e derivados presentes nos produtos de limpeza, são as cloraminas e os organoclorados. Além de cancerígenos, estes elementos se acumulam na cadeia alimentar e prejudicam a fauna e os seres humanos (ALIGLERI, ALIGLERI; KRUGLIANSKAS, 2016). 
Como descrito anteriormente, muitos domissanitários possuem tensoativos, em especial os detergentes que são compostos orgânicos anfifílicos, istoé, apresentam em sua estrutura química uma parte polar e hidrofílica (forte interação com a água) e outra apolar e hidrofóbica (pouca atração com a água), e que consegue promover a interação entre meios que apresentam polaridade diferente como, por exemplo, água e óleo (MARTINS, 2009).

Os tensoativos, quando em contato com os corpos hídricos, reduzem a tensão superficial água diminuindo sua taxa de evaporação e aumentando a solubilidade de compostos orgânicos presentes nos corpos hídricos e, além disso a espuma formada sobre a superfície da água diminui a penetração dos raios solares, reduz a solubilidade do oxigênio provocando a morte de micro-organismos, peixes e plantas aquáticas (OLIVEIRA; CÁSSIA, 2017).

Sendo assim, desde 1981 no Brasil, é proibida a venda de tensoativos de sulfonato de alquilbenzeno, pois apesar do seu grande poder de limpeza, seu potencial poluidor é muito alto (NETO; DEL PINO, 2001). Ele forma uma camada de espuma em corpos d'água, conhecida como cisne-de-detergente que carrega com ela diferentes categorias de poluentes, diminui a taxa de fotossíntese e aumenta a mortalidade de seres aquáticos, além disso, a porção hidrofóbica da molécula de sulfonato de alquilbenzeno não são passíveis de degradação biológica (OLIVEIRA; CÁSSIA, 2017).

Oliveira e Cássia (2017) realizaram uma pesquisa comparando as vantagens e desvantagens entre os surfactantes sintéticos e os biossurfactantes, apontando os pontos negativos. Quando em contato com corpos hídricos os surfactantes sintéticos causam a redução da tensão superficial da água diminuindo sua taxa de evaporação, o aumento da solubilidade de compostos orgânicos presentes nos corpos hídricos, a espuma formada sobre a superfície da água diminui a penetração dos raios solares, reduz a solubilidade do oxigênio provocando a morte de micro-organismos, peixes e plantas aquáticas sem contar o uso de matérias-primas não renováveis, principalmente os derivados do petróleo. Já os biossurfactantes, apresentam pontos positivos em relação aos sintéticos tais como um maior poder de limpeza, baixa toxicidade, biodegradabilidade, estáveis até em concentrações salinas e podem ser produzidos a partir de resíduos renováveis e agroindustriais.

Atualmente, os níveis de fosfatos nos detergentes são controlados por lei, mas o acúmulo dessas substâncias nos rios, lagos e praias, que recebem esgoto sem tratamento, pode prejudicar a vida das plantas e animais que vivem nestes locais, tendo em vista que os fosfatos favorecem a multiplicação de algas e cianobactérias, que em excesso prejudicam a oxigenação da água diminuindo a incidência de luz solar num processo chamado de eutrofização (TRATSCH, 2010).

A produção de produtos domissanitários, apesar da diversidade, são caracterizadas pelo alto consumo de água (MARTINS, 2009). Para a indústria é tida como uma das matérias-primas do processo de produção. Além disso, segundo Martins (2009, p.13) em sua pesquisa a respeito da indústria de domissanitários e seu processo produtivo, a água é usada "em sistema de resfriamento, na geração de vapor, bem como em procedimentos de limpeza e sanitização". 
A poluição das águas nos rios, lagos, mares e oceanos acontecem não apenas pelo despejo individual de uma substância, mas também pela reação química dos inúmeros produtos de limpeza usados nas residências: detergentes, sabão em pó, amaciante, sabonetes, shampoos, cremes dentais, desinfetantes, limpa-vidros, água sanitária, amoníaco, entre outros; essa combinação potencializa os impactos sobre a qualidade das águas, sobre a fauna e flora dos ecossistemas, assim como aumenta o perigo para as populações que consumirem estas águas ou se alimentarem desses animais aquáticos (MARTINS, 2009).

Souza et al. (2015) em sua pesquisa a respeito dos impactos dos produtos domissanitários na saúde da população do complexo do Alemão no Rio de Janeiro constatou que os consumidores dos produtos domissanitários muitas vezes não associam os domissanitários a produtos químicos tóxicos e dessa forma não utilizam com o cuidado necessário, mesmo contendo as instruções nos rótulos. A pesquisa ainda apontou que com a abundância de produtos, é difícil ter um controle do uso, das suas misturas e ter um dado específico a respeito dos produtos utilizados.

Apesar da dificuldade de se saber ao certo qual produto é utilizado com maior frequência pelos consumidores, devido aos nomes populares serem mais conhecidos, o hipoclorito de sódio (cloro) é o produto mais utilizado (SOUZA et al, 2015). A escolha desse produto, segundo Bramante, Lourenço e Candiani (2017), é feita de acordo com o poder de limpeza, o cheiro agradável e o fato de ser mais barato ou apresentar baixos custos.

O surgimento de novos produtos no mercado dos domissanitários o torna hiper-competitivo, em que através de campanhas publicitárias os produtos vão lutando por espaço (CORRÊA, 2005). Ressaltando o brilho, cheiro e a longa duração, os produtos mascaram os males que podem causar a saúde e ao meio ambiente (CORRÊA, 2005). Aos olhos do consumidor atual, uma consciência maior e valorização de condutas ecologicamente corretas têm surgido. (BURSZTYN; BURSZTYN, 2013). Com isso, algumas empresas hoje, para uma maior aceitação no mercado, estão cada vez buscando formas de trabalhar sem prejudicar o meio ambiente (BRANDALISE et al, 2014) trazendo para o mercado dos domissanitários produtos que minimizam o impacto ambiental, como os concentrados com menor utilização de água, detergentes de base biodegradável além de utensílios para a limpeza, como esponjas e vassouras, biodegradáveis.

Tendo em vista a necessidade de os domissanitários serem mais sustentáveis, percebe-se atualmente o surgimento de certificações para estes produtos. Aligleri, Aligleri e Kruglianskas (2016) destacam a certificação Cradle to Cradle (CTC) em produtos de limpeza. ACTC trabalha uma nova relação entre produção e consumo sem a geração de resíduos ou danos ao meio ambiente em que se cria um ciclo fechado de produção, os resíduos tornam-se nutrientes e todos os produtos e seus materiais devem retornar à indústria como matéria-prima de qualidade, após cada ciclo de uso. O objetivo é criar uma pegada ecológica positiva por produtos inteligentes com $100 \%$ de reciclabilidade, zero toxicidade e sem riscos para as pessoas e para o meio ambiente. Ainda nessa 
pesquisa foi constatado o déficit de empresas brasileiras certificadas, e ainda um pequeno número de certificações com $100 \%$ de adequação.

Além disso, os produtos sanitizantes podem ser certificados pelo IBD Certificações (Instituto Biodinâmico Certificações) em relação à matéria prima, embalagem, produção, rotulagem e práticas sócio ambientais.

\section{Percepção ambiental como ferramenta para a educação}

A percepção é a forma como o ser humano responde às ações do meio e esta ideia é formada a partir de experiências sensoriais estabelecidas ao longo da vida percebidas pelos órgãos do sentido, visão, tato, olfato, audição e paladar (CUNHA; LEITE, 2009). Apesar de todos os seres humanos compartilharem dos mesmos sentidos, suas percepções se diferenciam conforme a sua cultura e experiências, e as percepções pré estabelecidas pelo coletivo podem servir como fonte de influência para as percepções estabelecidas individualmente (PALMA, 2005).

A percepção ambiental é a forma que o ser humano se relaciona com o meio ambiente, podendo ser definida como sendo uma tomada de consciência do ambiente pelo homem, ou seja, o ato de perceber o ambiente que se está inserido, aprendendo a proteger e a cuidar do mesmo (CUNHA; LEITE, 2009). A educação ambiental utiliza da percepção ambiental como um instrumento para a defesa do meio natural, ajudando a aproximar o homem da natureza despertando uma maior responsabilidade e respeito dos indivíduos em relação ao ambiente em que vivem (FERNANDES; GORZA; PELISSARI; LARANJA; SOUZA, 2003).

A educação ambiental é importante para o aprendizado e a reavaliação de uma rede de significados, valores e conceitos sociais que permeiam as experiências ecológicas e busca desenvolver valores e habilidades para que os indivíduos adotem comportamentos ambientalmente adequados para um desenvolvimento sustentável e para melhoria da qualidade de vida de todos os povos (SILVA; HIGUCHI; FARIAS, 2015).

As atividades de educação ambiental quando eficazes tem como missão amadurecer o potencial do indivíduo como cidadão já que é no processo de aprendizagem que as questões de cidadania e responsabilidade social são fortalecidas e estas competências são vitais na constituição das pessoas para assimilação de mudanças, tornando-se autônomas em suas escolhas, respeitando as diferenças e respeito aos recursos ambientais (HIGUCHI; ALVES; SACRAMENTO, 2009).

Conclui-se que a educação ambiental tem o papel de alterar a percepção ambiental de forma positiva de modo a formar uma população que entenda o espaço que ela vive e seus impactos, ainda fomentando o conhecimento de que ela é geradora de processos que agridem o meio ambiente e capaz de modificar o seu próprio meio (PALMA, 2005). Pode trazer como solução, atividades que estimulem os sentidos para poder ser inserido em seu cotidiano hábitos mais saudáveis para o meio ambiente (FERNANDES; GORZA; PELISSARI; LARANJA; SOUZA, 2003). 


\section{OBJETIVOS}

Este artigo pretende descrever e analisar os resultados da atividade de extensão promovida pelo edital PROEX 16/2019 no IFSC Campus Garopaba a respeito dos produtos domissanitários e sua relação com o grupo. Dessa forma, estimular o diálogo em relação aos problemas ambientais e à saúde que estão diretamente relacionados a eles. Para contribuir para uma educação ambiental mais ampla das comunidades de Garopaba e Imbituba em Santa Catarina.

\section{METODOLOGIA}

Essa atividade se caracteriza como uma ação de extensão, e para sua elaboração foram utilizadas metodologias participativas no formato investigação-ação.

As atividades foram realizadas em um dia específico com duração de 3 horas, marcadas antecipadamente, no período vespertino com frequentadoras dos Grupos de Mães dos bairros da Costa do Macacu (18 participantes) e Areias do Macacu (19 participantes) em Garopaba (SC) , do Grupo de Mães da Barra de Ibiraquera (16 participantes) em Imbituba (SC) e das mulheres participantes do projeto Mulheres Sim do IFSC Campus Garopaba (12 participantes), além disso foi realizada uma atividade piloto com o CAPS.

A amostra desta atividade se caracterizou como não-probabilística e os participantes foram subgrupos já formados na população. Para acessar os responsáveis por estes grupos foram feitos alguns contatos com os responsáveis pelo projeto Mulheres Sim e os agentes de saúde da região, que encaminharam a atividade para os grupos de mães. No total tiveram 65 participantes, todas mulheres e mais da metade com mais de 45 anos, $48 \%$ delas frequentam o Ensino Fundamental sendo que apenas 11\% delas ingressaram no Ensino Superior.

As atividades foram estruturadas em três momentos. No primeiro, foi aplicado o questionário estruturado com perguntas abertas e fechadas para conhecer o público e dimensionar o projeto de extensão de uma forma mais personalizada para a realidade local. Foram abordados temas como escolaridade, produtos utilizados em suas residências, hábito de leitura dos rótulos, utilização de equipamento de proteção individual (EPI), conhecimento dos problemas para saúde humana e também quanto a percepção prévia dos impactos ambientais dos produtos utilizados na limpeza.

No segundo, foi realizada uma exposição dialogada, utilizando-se de uma apresentação de slides contendo informações a respeito dos produtos domissanitários e seus impactos, seguida por uma apresentação dos rótulos dos produtos, importância da utilização de EPI, demonstração de utensílios biodegradáveis para a limpeza, como a bucha vegetal. Foi demonstrado também o processo de tintura natural para a aromatização e óleos essenciais, com o objetivo de sensibilizar as participantes ao cheiro além da confecção de alguns produtos caseiros tais como limpa vidros, detergente de sabão de coco, desodorante de ambientes e tira mofo. Estes produtos foram escolhidos para serem produzidos para serem percebidos pelas participantes que com produtos 
simples pode-se fazer diversas misturas com os mesmos ingredientes para diferentes ambientes, evitando comprar produtos específicos e diminuindo a quantidade de domissanitários nas residências.

Ademais o ambiente da oficina foi preparado para haver um contato atencioso aos produtos de limpeza convencionais, sendo eles os produtos vendidos no supermercado, trazendo uma exposição física deles e uma leitura das informações contidas no rótulo.

No terceiro e último momento, houve a demonstração de receitas de produtos de limpeza mais ecológicos. Os resultados foram coletados e agrupados por semelhança de resposta possibilitando a elaboração de tabelas e gráficos dos resultados obtidos. Dessa forma, foi possível visualizar informações a respeito da percepção e utilização de produtos domissanitários pelo grupo.

\section{RESULTADOS E DISCUSSÃO}

As respostas dadas às perguntas do questionário inicial aplicado geraram informações que traduziram a percepção prévia de 65 participantes em relação aos domissanitários e os problemas ambientais gerados por eles. Buscando mapear quais são os produtos mais utilizados nos lares dos participantes, dados coletados apontaram que o desinfetante e a água sanitária estão presentes em 78,5 \% das casas dos entrevistados, seguido pelo detergente com $72,3 \%$ e o sabão em barra 55,4\%. Isso reafirma a presença do cloro em $70 \%$ das casas brasileiras, conforme apontado por um estudo realizado por Martins (2009) que apresentou a mesma porcentagem em seu estudo. Ademais, 66,3\% das participantes alegaram utilizar produtos caseiros para limpar determinada parte das casas, sendo eles: sabão, limpa vidros elaborados com vinagre e álcool, tira mofo feito com vinagre e água.

O grau de importância na hora da compra, em relação ao cheiro, preço, poder de limpeza, rendimento e marca estão expressos no gráfico 1. Percebe-se que o poder de limpeza é o fator mais decisivo na hora da compra do consumidor, seguido do cheiro agradável. Já o fator de menor importância foi a marca do produto, podendo constatar que a fabricação de produtos ecológicos eficientes por pequenas empresas não ficaria em desvantagem em relação a produtos de grandes marcas. É importante ressaltar que o preço não apareceu como decisivo.

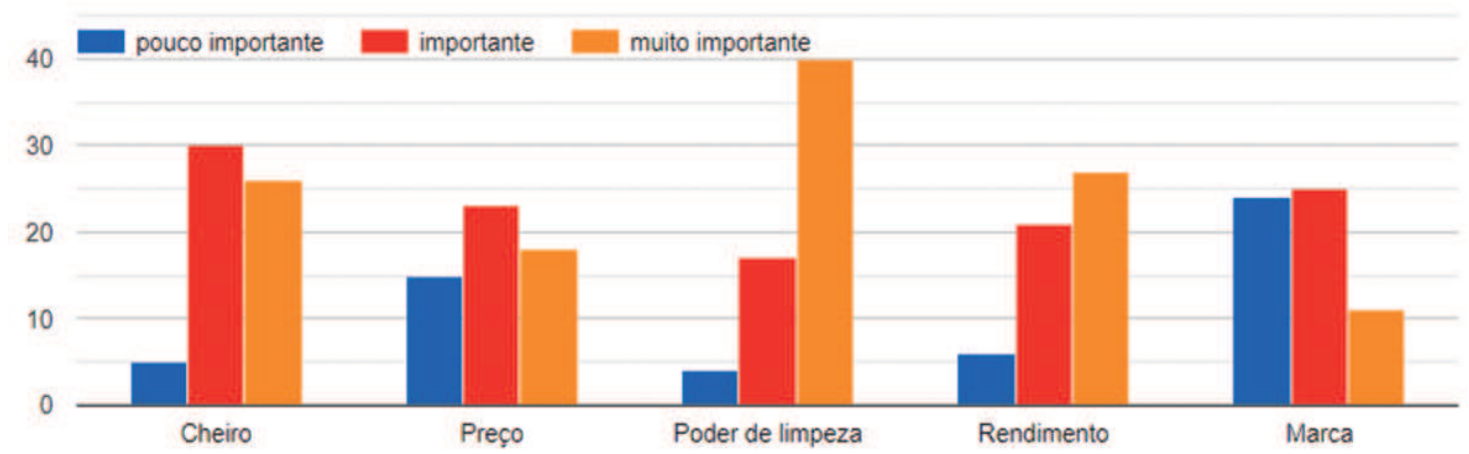

Gráfico 1 - Fatores decisivos para a compra de domissanitários por mulheres da região de Garopaba e Imbituba. Fonte: Dados primários coletados. 
Quando questionados sobre a leitura dos rótulos, apenas 12\% alegaram ler com frequência. Um total de 11,7\% acreditam entender o que está escrito e apenas 13\% disseram seguir as instruções contidas. Dessa forma, pode-se concluir que a falta de leitura do rótulo é um agravante para a má utilização destes produtos, tendo em vista que o rótulo é a comunicação direta entre o fabricante e o consumidor, pois traz a forma correta de utilização, as precauções, formas de armazenamento, validade e data de produção, riscos, ingredientes, periculosidade, além de propagandas.

Um total de $98 \%$ das participantes afirmaram conhecer os males à saúde humana causados pelo domissanitários quando utilizados de forma incorreta. Mesmo assim, 52,4\% alegaram nunca utilizar EPI para a realização das atividades. A não utilização de EPI é um agravante para a recorrência de problemas de saúde, sendo que, nesta pesquisa 36\% informaram que já tiveram algum problema de saúde relacionado ao uso destes produtos, sendo as mais frequentes alergias na pele e problemas respiratórios.

Os impactos ambientais dos domissanitários se mostraram desconhecidos para 41,9\% das participantes. Quanto ao destino das embalagens, a maioria (49,2\%) descartou no lixo comum (Gráfico 2). O fato de 15,4\% das participantes utilizarem estas embalagens em casa para outros fins é um dado que deve ser analisado com mais profundidade em um trabalho futuro, pois nem sempre a reutilização é feita de modo adequado.

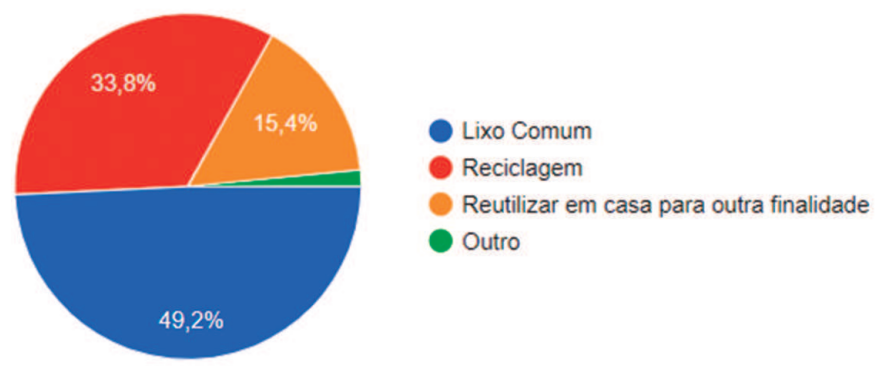

Gráfico 2 - Descarte das embalagens dos produtos domissanitários por mulheres da região de Garopaba e Imbituba.

Fonte: Dados primários coletados.

Já a água utilizada com produto de limpeza, em sua maioria, o descarte é feito no tanque (Gráfico 3). Ainda aquelas que tem a casa na beira da lagoa, como as participantes da Costa do Macacu e da Ibiraquera, alegaram se preocupar com o local de descarte da água residual do processo de limpeza doméstica, já que o contato com o ecossistema da lagoa é direto e muitas vezes sua renda vem da própria propriedade.

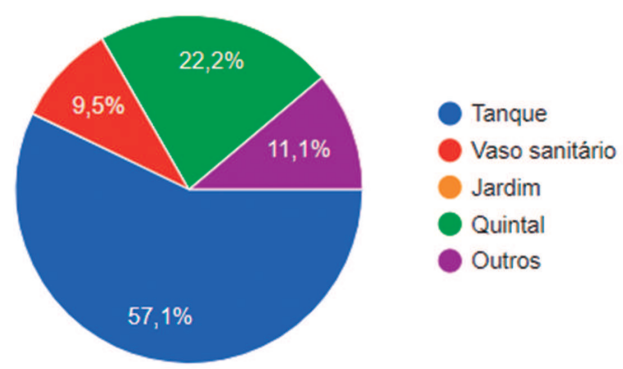

Gráfico 3 - Descarte da água residual da limpeza doméstica de mulheres da região de Garopaba e Imbituba Fonte: Dados primários coletados. 
A compra de produtos ecológicos ainda não é uma realidade, pois 94\% das participantes alegaram nunca terem comprado. Os $6 \%$ que compraram produtos ecológicos afirmaram que a experiência foi positiva. Ainda que os produtos caseiros apareçam verbalmente, sua confecção é, na maioria, feita por terceiros.

Em relação ao local onde estes produtos são guardados, os resultados que mais apareceram foi que os domissanitários são guardados na área de serviço, em armário fechado e no banheiro. Das participantes, $13 \%$ declararam não ter um local fixo para fazer o acondicionamento deste produto, e que ele é feito de diversas formas. Um total de $28 \%$ das participantes destacaram a necessidade de guardar fora do alcance de crianças e em um espaço na lavanderia. Como consequência de um público das oficinas formado por mulheres mães, a proteção das crianças foi relatada pela maioria, sendo elas a necessidade de guardar estes produtos fora do alcance, de procurar aromas que não sejam agressivos à respiração e reduzir a utilização do cloro.

Durante a apresentação da oficina, as participantes relataram sobre produtos de limpeza caseiros preparados e utilizados por elas, com matérias primas recicladas, como óleo de reuso. Alegaram ter uma preocupação relacionada ao impacto na saúde, pela utilização dos produtos domissanitários, mas ainda assim, os impactos ambientais produzidos pelos domissanitários não são um fator de decisão na hora da compra.

No decorrer da atividade, foram apontados pelas participantes comentários relacionados a preocupação com produtos que não podem ser ingeridos, trazendo a ideia de que com esta característica o torna perigoso. Durante a fabricação dos produtos, foram relatados pelas participantes produtos que elas utilizam, muitos semelhantes aos propostos na oficina.

Ainda no desenvolvimento da exposição dialogada, apareceram as dificuldades na leitura do rótulo. A pesquisa, em sua maioria, foi feita com mulheres que não concluíram seus estudos de nível médio, então como resultado apareceram comentários a respeito da dificuldade na compreensão do que está escrito e principalmente no tamanho da letra contida nos rótulos. Sendo estes os principais motivos apontados por elas para a não leitura dos mesmos. Com isso pode-se relacionar a dificuldade na leitura dos rótulos com a má utilização destes produtos, intensificando os impactos ambientais causados por eles. Além disso, a falta de utilização do EPI aumenta o risco de problemas de saúde para quem utiliza os produtos domissanitários. Com isso, reforçou-se durante as oficinas a instrução de se utilizar os EPIs, pois assim o número de intoxicação tende a diminuir.

A principal reclamação, aliada aos produtos de limpeza convencionais adquiridos no mercado, apontada pelas participantes foi o cheiro forte, apesar de o cheiro ter aparecido como um fator de compra. Além disso, a falta dos produtos ecológicos nas prateleiras dos mercados foi alegado como o principal motivo para a escolha de produtos convencionais.

As mulheres participantes alegaram, que nunca haviam sido questionadas sobre estes produtos e tão pouco tido contato com informações sobre os mesmos. Conforme dados coletados, os hábitos nas atividades domésticas foram construídos com base no que é passado por gerações. 
Dessa forma, o envolvimento das participantes na oficina gerou grande discussão sobre os problemas ambientais e sobre a saúde humana gerados pelos domissanitários, assim como também as sensibilizou para fazer novas escolhas mais sustentáveis criando uma percepção ambiental a respeito destes produtos utilizados diariamente. Podendo-se assim, gerar uma mudança na cultura e nos hábitos dos participantes.

Quanto à avaliação da oficina aplicada ao final da atividade, $76 \%$ afirmaram ter obtido novos conhecimentos com a participação e recomendaria esta atividade a outras pessoas. Além disso, $70 \%$ afirmaram que após a atividade estão mais cientes dos impactos ambientais causados pelos produtos domissanitários.

\section{CONCLUSÕES}

Este projeto atingiu seu principal objetivo, sendo ele a difusão de conhecimentos a respeito dos produtos domissanitários, ampliando o conhecimento da população em relação aos problemas ambientais que estão diretamente relacionados a eles, contribuindo para uma educação ambiental mais ampla das comunidades de Garopaba e Imbituba em Santa Catarina.

A análise dos resultados apresentados permitiu concluir que, apesar de as pessoas terem uma ideia do perigo para o meio ambiente e para saúde humana que os produtos domissanitários causam, as práticas de bom uso, ou seja, a leitura e compreensão dos rótulos, utilização de EPI, descarte dos resíduos resultantes da limpeza e as suas embalagens, ainda não são realizadas de forma adequada.

Notou-se com os argumentos dos participantes das oficinas que a indústria de saneantes precisa de reformulações para se adequar ao consumidor consciente, compreendendo que existe uma necessidade de investimento neste setor, pois a cada ano este público aumenta.

Assim sugere-se que esta atividade seja ampliada para um maior grupo para que tornem-se ainda mais significativos quantitativamente e assim possam atingir os fabricantes. Já que, com a motivação do consumidor para a compra de produtos menos agressivos ao meio ambiente, estimula diretamente os produtores a disponibilizarem estes produtos menos agressivos no mercado. Pesquisas referentes à eficácia de produtos caseiros utilizados na limpeza, tais como vinagre, bicarbonato de sódio também poderiam ser realizadas, pois observa-se, na prática, a utilização destes ingredientes nas rotinas de limpeza.

\section{REFERÊNCIAS}

ALIGLERI, Lilian; ALIGLERI, Luiz Antonio; KRUGLIANSKAS, Isak. Cradle to Cradle: Uma Análise dos Produtos Certificados para Limpeza Geral e Lavagem de Roupa. Gestão. Org, v. 14, p.88-96, 2016.

ANVISA, Resolução da diretoria colegiada-RDC No 14, de 28 de fevereiro de 2007. Disponível em: <http://portal.anvisa.gov.br/documents/10181/2718376/RDC_14_2007.pdf/3eda65f3-5e07-40b 5-b3fbc85bfdcabec6 >. Acesso em: 21 Maio 2019.

ANVISA, Resolução de Diretoria Colegiada - $\mathrm{RDC} \mathrm{n}^{\circ}$ 43, de 1 de setembro de 2005. Diário Oficial da União. Brasil: Ministério da Saúde. 
ANVISA, Resolução de Diretoria Colegiada - $\operatorname{RDC}^{\circ}$ 55, de 10 de novembro de 2009. Diário Oficial da União. Brasil: Ministério da Saúde.

ANVISA, Resolução de Diretoria Colegiada-RDC nº 110, de 8 de setembro de 2016. Diário Oficial da União. Brasil: Ministério da Saúde.

BRAMANTE, Beatriz Colosso; LOURENÇO, Ana Valeria Santos de; CANDIANI, Giovani. Investigação sobre usos e manuseios de produtos saneantes por alunos, professores e donas de casa da região metropolitana de São Paulo - Brasil. Enseñanza de Las Ciencias, São Paulo, n. extra, p.47214726, set. 2017.

BRANDALISE, Loreni Teresinha; BERTOLINI, Geysler Rogis; ROJO, Claudio Antonio; LEZANA, Álvaro Guillermo Rojas. Classificação de produtos ecologicamente corretos. Revista Metropolitana de Sustentabilidade, Paraná, v. 4, n. 2, p.01-22, maio 2014. Disponível em: < https://revistaseletronicas.fmu.br/ index.php/rms/article/view/192 >. Acesso em: 27 Abr. 2019.

BRASIL. Lei nº 6938, de 31 de agosto de 1981: Política Nacional do Meio Ambiente, 1981.

BURSZTYN, Maria Augusta; BURSZTYN, Marcel. Fundamentos de política e gestão ambiental: Caminhos para sustentabilidade. Rio de Janeiro: Editora Garamond Ltda, 2013.599 p.

CORRÊA, Lilia Modesto Leal. Saneantes domissanitários e saúde: Um estudo sobre a exposição de empregadas domésticas. 2005. Dissertação (Mestrado em Saúde Coletiva) - Curso de Saúde Coletiva, Universidade Federal do Rio de Janeiro, Rio de Janeiro, 2005.

CUNHA, Alecsandra Santos da; LEITE, Eugênio Batista. Percepção Ambiental: Implicações para a educação ambiental. Sinapse Ambiental, Minas Gerais, p.66-80, 2009.

DIAS, Reinaldo. Gestão Ambiental: Responsabilidade Social e Sustentabilidade. 2. ed. São Paulo: Editora Atlas, 2011.

FERNANDES, Roosevelt da S.; PELISSARI, Vinicius B.; GORZA, Leonardo Santos; LARANJA, Andréa Coelho; SOUZA, Valdir José de. Percepção ambiental dos alunos da Faculdade Brasileira - UNIVIX, Vitória, ES. Revista Científica: UNIVIX. Vol 1. Vitória, ES. 2003.

FOOK, Sayonara Maria Lia; AZEVEDO, Esthefanye Fernandes de; COSTA, Monalisa Maciel; FEITOSA, Itavielly Layany França; BRAGAGNOLI, Gerson; MARIZ, Saulo Rios. Avaliação das intoxicações por domissanitários em uma cidade do Nordeste do Brasil. Cadernos de Saúde Pública, v. 29, n. 5, p.10411045, 2013.

GIL, Antonio Carlos. Métodos e técnicas de pesquisa social. 6. ed. São Paulo: Atlas, 2008.

HUNGER, Dagmar; ROSSI, Fernanda; PEREIRA, Juliana Martins; NOZAKI, Joice Mayumi. O dilema extensão universitária. Educação em Revista, v. 30, n. 3, p.335-354, 2014.

HIGUCHI, Maria Inês Gasparetto; ALVES, Heloisa Helena Stopatto Cruz; SACRAMENTO, Luiza Conceição. A arte no processo educativo de cuidado pessoal e ambiental. Currículo sem Fronteiras, v. 9, n. 1, p. 231-250, 2009.. 
IBGE - INSTITUTO BRASILEIRO DE GEOGRAFIA E ESTATÍSTICA. Mulheres dedicam quase o dobro do tempo dos homens em tarefas domésticas. 2018. Disponível em: <https://agenciadenoticias.ibge.gov.br/ agencia-noticias/2012-agencia-de-noticias/noticias/24267-mulheres-dedicam-quase-o-dobro-do-tempo-doshomens-em-tarefas-domesticas >. Acesso em: 13 Nov. 2019.

MARCONI, Marina de Andrade; LAKATOS, Eva Maria. Metodologia do trabalho científico. 8. ed. São Paulo: Atlas Ltda, 2017. 239 p.

MARTINS, Frederico Venâncio. A indústria de saneantes domissanitários e seu processo produtivo. 2009. 26 f. Curso de Bacharelado em Química Industrial, Universidade Estadual de Goiás, Anápolis, 2009.

NETO, Odone Gino Zago; DEL PINO, José Claudio. Trabalhando a química dos sabões e detergentes. Universidade Federal do Rio Grande do Sul - UFRS - Instituto de Química. 2001. Disponível em: < www. iq.ufrgs.br/aeq/html/publicacoes/matdid/livros/pdf/sabao.pdf> . Acesso em 03 Out. 2019.

NUNES, Ana Lucia de Paula Ferreira Nunes; SILVA, Maria Batista da Cruz. A extensão universitária no ensino superior e a sociedade. Mal Estar e Sociedade, Barbacena, v. 4, n. 7, p.119-133, 2011.

OLIVEIRA, Felipe Lorena de; CÁSSIA, Dias Sandra de. Surfactantes sintéticos e biossurfactantes: vantagens e desvantagens. Química Nova na Escola, v. 39, n. 3, p.228-236, 2017.

PALMA, Ivone Rodrigues. Análise da percepção ambiental como instrumento ao planejamento da educação ambiental. 2005. 83 f. Dissertação (Mestrado) - Curso de Engenharia, Universidade Federal do Rio Grande do Sul, Porto Alegre, 2005.

SILVA, Winnie Gomes da; HIGUCHI, Maria Inês Gasparetto; FARIAS, Maria Solange Moreira de. Educação ambiental na formação psicossocial dos jovens. Ciência \& Educação (Bauru), v. 21, n. 4, p.1031-1047, dez. 2015.

SOUZA, Rodrigo Otavio L. de; FILHO, José T. de Seixas; MIRANDA, Maria Geralda de; NETO, Francisco Moysés de Carvalho. O Impacto dos Produtos Domissanitários na Saúde da População do Complexo do Alemão - Rio de Janeiro. Química Nova na Escola, v. 37, n. 2, p.93-97, 2015.

TRATSCH, Mauricio Vicente Motta. Gestão de resíduos de uma indústria de produtos de limpeza. Santa Maria, 2010. Dissertação (Mestrado em Engenharia de Produção). Programa de Pós-Graduação em Engenharia de Produção. Universidade Federal de Santa Maria.

Submetido em: 01/03/2021 Aceito em: 04/08/2021. 